Socioeconomic status and child health

\section{Disentangling the effects of different components of socioeconomic status on health in early childhood}

\section{Nick J Spencer}

\section{Impact of material hardship on child health}

$\mathrm{T}$ he effects of poverty on health in early childhood have been recognised for many years and have generated a prolonged and often acrimonious causal debate. ${ }^{1}$ Explanations have broadly fallen into two groups: those that focus on characteristics of the poor themselves such as the inferiority of their "genetic stock", their poor hygiene, their poor childcare practices, or their health related behaviours such as smoking and those that focus on the effects of poverty itself and the societal structures that generate it.

Given the longstanding interest in poverty and child health, it is surprising that, as Séguin et al ${ }^{2}$ state in their paper in this issue of the journal, the aspects of socioeconomic status that are important to children's health remain unclear. Part of the explanation for this continuing lack of clarity lies in the tendency to treat different components of socioeconomic status as adequate proxies for the complex constellation of factors that constitute socioeconomic status. For example, UK studies have been heavily reliant on the registrar general's social class, a measure based on the occupation of the head of the household, which has been shown to be of limited value in the study of maternal and child health. ${ }^{3}$ US studies, using the official poverty line to create a poor/ non-poor dichotomy, have been shown to underestimate the effects of severe and long term poverty on child health and development. ${ }^{4}$

A component of socioeconomic status that has been extensively used in studying child health, especially in less developed countries but also in developed countries, is maternal education. Education is seen as a powerful promoter of child health and as a means of breaking the so called "cycle of deprivation". ${ }^{5}$ The resultant research and policy attention on promoting parental skills through education $^{6-8}$ shifts the focus away from the societal determinants of family and child poverty towards the perceived failings of poorly educated mothers. However, educational attainment is strongly correlated with the socioeconomic status of family of origin' and educational opportunity depends as much on family income as cognitive ability. ${ }^{10}$ Cognitive ability itself is sensitive to adverse social circumstances in early childhood. ${ }^{11}{ }^{12}$

The paper by Séguin et al is an important addition to the literature on poverty and health in early childhood. ${ }^{2}$ It is methodologically sound and is based on prospective data collection in a large cohort with a very small attrition rate. The paper investigates the impact of material hardship, inadequate income to meet needs, not simply income and the analysis accounts for important potential confounders such as maternal education. Material hardship has not been widely used as a measure of the financial aspects of socioeconomic status and its use in this study overcomes some of the problems of misclassification bias associated with current income and other income proxies such as occupational class and housing tenure. The longitudinal methodology also allows the authors to distinguish short term and long term material hardship. The results suggest that, at least in the Quebec context, longstanding material hardship has an effect, independent of maternal education, on a range of health related outcomes in early childhood.

The findings in the paper of Séguin $e t$ al raise important questions for future research into the social determinants of health in early childhood and, if confirmed in further studies, have major policy implications. ${ }^{2}$ Further studies in different countries will be required to confirm the independent impact of material hardship on child health. The differential impact of material hardship and maternal education may vary with the health outcomes studied. Séguin et $a l^{2}$ studied the impact on acute illness, asthma, hospitalisation, and growth; however, maternal education may account for more of the influence of material hardship on other outcomes, for example, child mental health. Further studies of a range of different health outcomes are needed to resolve these questions.

The issues raised by this paper are not simply arcane problems of research methodology. They have potentially far reaching policy implications. If the findings that material hardship has an impact on child health independent of maternal education are confirmed then policy responses based primarily on educating mothers rather than alleviating material hardship are likely to be unsuccessful. As Séguin et al suggest, social policies would need to ensure that all families with a young child have sufficient income. ${ }^{2}$ In the UK, US, Canada, and elsewhere, this represents a considerable challenge to the policy directions of current governments.

J Epidemiol Community Health 2005;59:2. doi: 10.1136/jech.2004.027789

Correspondence to: Professor N J Spencer, School of Postgraduate Medical Education, University of Warwick, Coventry CV4 7AL, UK; n.j.spencer@warwick.ac.uk

\section{REFERENCES}

1 Spencer NJ. Poverty and child health. 2nd ed. Abingdon: Raddliffe Medical Press, 2000.

2 Séguin $L, X u Q$, Gauvin $L$, et al. Understanding the dimensions of socioeconomic status that influence toddlers' health: unique impact of lack of money for basic needs in Quebec's birth cohort. $J$ Epidemiol Community Health 2005;59:42-8.

3 In: Glendinning C, Millar J, eds. Women and poverty in Britain. Hemel Hempstead: Harvester Wheatsheaf, 1987

4 Duncan GJ, Brooks-Gunn J, Klebanov PK Economic deprivation and early childhood development. Child Dev 1994;65:296-318.

5 HM Treasury. Child poverty review. London: Stationery Office, 2004 (http://www. hm-treasury.gov.uk).

6 Caldwell J, McDonald P. Influence of maternal education on infant and child mortality:levels and causes. Population Studies 1982;33:395-413.

7 Scott S, Spender Q, Doolan M, et al. Multicentre controlled trial of parenting groups for antisocial behaviour in clinical practice. BM 2001;323:194-7.

8 Hartman RR, Stage SA, Webster-Stratton C. A growth curve analysis of parent training outcome: examining the influence of child risk factors (inattention, impulsivity and hyperactivity problems), parental and family risk factors. J Child Psychol Psychiatry 2003;44:388-98.

9 Sigle-Rushton W. Intergenerational and lifecourse transmission of social exclusion in the 1970 British cohort study. London: Centre for Analysis of Social Exclusion, London School of Economics, 2004 (htttp://sticerd.lse.ac.uk/case/ $\mathrm{cp} /$ casepaper78.pdf).

10 Sacker A, Schoon I, Bartley M. Social inequality in educational achievement and psychosocial adjustment throughout childhood: magnitude and mechanisms. Soc Sci Med 2002:55:863-80.

11 Feinstein L. Inequality in the early years cognitive development of British children in the 1970 cohort. Economica 2003;70:73-97.

12 Brooks-Gunn J, Duncan GJ. The effects of poverty on children. Future Child 1997;7:55-71. 
Aspirin

\section{What next for low dose aspirin?}

\section{Gareth Morgan}

\section{Report from a conference on the public health potential of aspirin.}

A spirin (acetylsalicylic acid) is inexpensive, readily available, and widely used for the treatment of many common conditions. Undoubtedly, its most important use now is in vascular disease as a daily low dose (75$150 \mathrm{mg}$ ) leads to a substantial reduction in the risk of a vascular event or death. ${ }^{2}$ However, the drug is also associated with undesirable effects, most notably gastrointestinal irritation and bleeding, ${ }^{3}$ which limit its use.

Evidence is now accumulating that suggests that aspirin may confer a risk reduction against a range of other chronic diseases, in particular against cancer ${ }^{4}$ and possibly Alzheimer's disease. ${ }^{5}$ Because of the established benefits in vascular disease and these possible further benefits, aspirin would seem to have far reaching public health potential. So should it be more widely promoted?

This question was raised at a conference "The public health potential of aspirin in Wales" organised by the Welsh Aspirin Group (WAG) on 6 May 2004. WAG chairman Professor Peter Elwood suggested that a public health strategy to promote the use of low dose aspirin should be carefully examined. As with other preventive programmes, such as influenza vaccination, the strategy he proposed would have two arms: the targeting of high risk patients and a general population approach based upon age alone.

The present policy in Wales for the reduction of vascular disease involves only the first of these. High risk patients, such as those with angina pectoris, hypertension, diabetes mellitus, or a prior vascular event, are identified and prophylactic measures targeted to them. The results of a very recent survey of patients in a representative sample of general practices across Wales were presented (Elwood, personal communication) showing that only about half the patients at high vascular risk are actually taking aspirin. Efforts to increase the use of aspirin in all patients at high risk, who are without a contraindication, are therefore needed as a matter of urgency. It was also recommended that the use of aspirin during the acute infarction phase, whether taken by the patients themselves ( so called "immediate" aspirin), or given by para- medics ( so called "early" aspirin) should be factored into the high risk arm of the public health strategy. ${ }^{6}$

It was argued, however, that the present policy for vascular prophylaxis only in high risk patients is deceptive as well as being inefficient. Evidence from the south Wales Caerphilly cohort study was used to show that less than half the vascular events that occur in a community occur among those subjects who have been defined as being at high vascular risk. Although the evidence was derived from a study on men, similar findings would reasonably be expected for women.

The conference therefore went on to consider the benefits of an extension of aspirin prophylaxis beyond patients identified as being at high risk. The incidence of vascular events increases with age and there will therefore be an average age within a community at which the overall benefit of taking low dose aspirin outweighs the risk of undesirable effects. Evidence from the Caerphilly cohort study was again briefly presented to illustrate that the men at about 50 years of age had an average vascular risk above that at which aspirin is usually recommended, namely a five year risk of $3 \% .^{7}$ Although no comparable data are available for women in Wales, the vascular benefits of aspirin have been recommended elsewhere for post-menopausal women ${ }^{7}$ and most of these will be aged 50 years and over.

In addition, the evidence on aspirin and both cancer and Alzheimer's disease was considered. It was argued that although data from a number of sources suggest benefit from aspirin in these conditions, the evidence is at present inconclusive. The case for low dose aspirin must therefore be based on the vascular effects of the drug alone and any additional benefits would be a bonus.

The proposal was therefore made that vascular prophylaxis by low dose aspirin should be recommended on the basis of age alone. However, two important qualifications to the proposal were highlighted. Firstly, the evidence on the established and possible further benefits of low dose aspirin together with the evidence on the undesirable effects of the drug should be widely and repeatedly publicised. Aspirin is readily available and people should be encouraged to consider the possible benefits and risks for themselves and make their own informed decision about whether or not to take a low daily prophylactic dose. Secondly, aspirin must be recommended as a complement and not as an alternative to other measures that improve health. These include dietary and lifestyle changes as well as any drug regimen other than aspirin that may be advised for an individual patient.

A number of formal responses were made to the proposal of aspirin prophylaxis on the basis of age alone. The perspectives of the responses were from clinical medicine, public health, health policy, and health economics. They all expressed caution. For example, a clinician highlighted the paradox that exists between individuals and populations, in that some individuals who take aspirin may experience undesirable effects yet the population as a whole is likely to benefit. From a public health perspective it was observed that problems would follow if there were differential and inappropriate uptake of aspirin prophylaxis namely widening health inequalities and an increase in undesirable effects respectively. The health policy perspective drew attention to the present context in which such a strategy would be launched and recent controversies, such as MMR vaccination, that have affected public confidence in health services. From a health economics perspective the need for rigorous evaluation was emphasised, given that any prophylactic strategy will generate costs to individuals, to society, and to health services.

Considerable media interest plus feedback after the conference confirmed that the objective of increasing the profile of the public health potential of aspirin had been met. So what should happen next? While it is clear that efforts to increase the use of aspirin in all patients at high risk are urgently needed in Wales and other countries, ${ }^{8}$ the proposal of aspirin prophylaxis on the basis of age alone requires further consideration and an extensive process of public involvement. National public health agencies in the UK and other countries would seem to be the appropriate bodies to take a lead in this with possibly the World Health Organisation taking a coordinating role. In addition, there is a need for further research on aspirin and naturally occurring salicylates on the risk of non-vascular chronic diseases such as cancer. ${ }^{9}$ WAG is planning to convene a multidisciplinary exploratory workshop on salicylates in human health and disease. 


\section{ACKNOWLEDGEMENTS}

The above is largely based on discussions at a conference "The public health potential of aspirin in Wales" organised by the Welsh Aspirin Group (WAG) on 6 May 2004. Gareth Morgan is secretary to the Welsh Aspirin Group and will provide a copy of the conference report on request.

J Epidemiol Community Health 2005;59:3-4. doi: 10.1136/jech.2004.026260

Correspondence to: Mr G Morgan, Welsh Aspirin Group, 41 Ffordd Beck, Gowerton, Swansea SA4 3GE, UK; gareth.morgan@nphs. wales.nhs.uk

Funding: none.

Conflicts of interest: none declared.

\section{REFERENCES}

Antithrombotic Trialists' Collaboration Collaborative meta-analysis of randomised trials of antiplatelet therapy for prevention of death, myocardial infarction, and stroke. BM 2002;324:71-86

2 Weisman SM, Graham DY. Evaluation of the benefits and risks of low-dose aspirin in the secondary prevention of cardiovascular and cerebrovascular events. Arch Intern Med 2002; 162:2197-202.

3 Serrano $\mathbf{P}$, Lanas A, Arroyo MT, et al. Risk of upper gastrointestinal bleeding in patients taking low-dose aspirin for the prevention of cardiovascular diseases. Aliment Pharmacol Ther 2002; 16:1945-53.

4 Baron JA. Epidemiology of non-steroidal antiinflammatory drugs and cancer. Prog Exp Tumor Res 2003;37:1-24.

5 Etminan M, Sudeep G, Samii A. Effect of nonsteroidal anti-inflammatory drugs on risk of
Alzheimer's disease: systematic review and metaanalysis of observational studies. BMJ 2003;327:128-30.

6 Woollard M, Smith A, Elwood P. Pre-hospital aspirin for suspected myocardial infarction and acute coronary syndrome: a headache for paramedics? Emerg Med 2001;18:478-81.

7 Hayden M, Pignone M, Phillips C, et al. Aspirin for the primary prevention of cardiovascular events : a summary of the evidence for the US Preventive Services Task Force. Ann Intern Med 2002; 136:161-72.

8 Carroll K, Majeed A, Firth C, et al. Prevalence and management of coronary heart disease in primary care: populationbased cross-sectional study using a disease register. J Public Health Med 2003;25:29-35.

9 Morgan G. Should aspirin be used to counteract salicylate deficiency? Pharmacol Toxicol 2003;93:153-5

\section{THE JECH GALLERY}

\section{Cholera and a tale of two cities}

O ne of the great tales of public health imbibed with all students on their Masters of Public Health course, is that of John Snow and the Broad Street pump. Sidney Chave's tabulation of the daily cases illustrates how the epidemic had already peaked on 1 September, whereas Snow removed the handle off the pump on 8 September. The secret to success in public health, the cynic has argued, is to ride the downward wave of epidemics.

Meanwhile in 1854, 200 miles up the road in Liverpool, England's first Medical Officer of Health, William Henry Duncan was tackling another outbreak attributed to direct contagion in the grossly overcrowded slums. That outbreak peaked around 22 September. Was it affected by Duncan's measures, based on environmental hygiene?

John R Ashton

North West Public Health Team, Department of Health, 18th Floor, Sunley Tower, Piccadilly Plaza, Manchester MI 4BE, UK johnrashton@blueyonder.co.uk
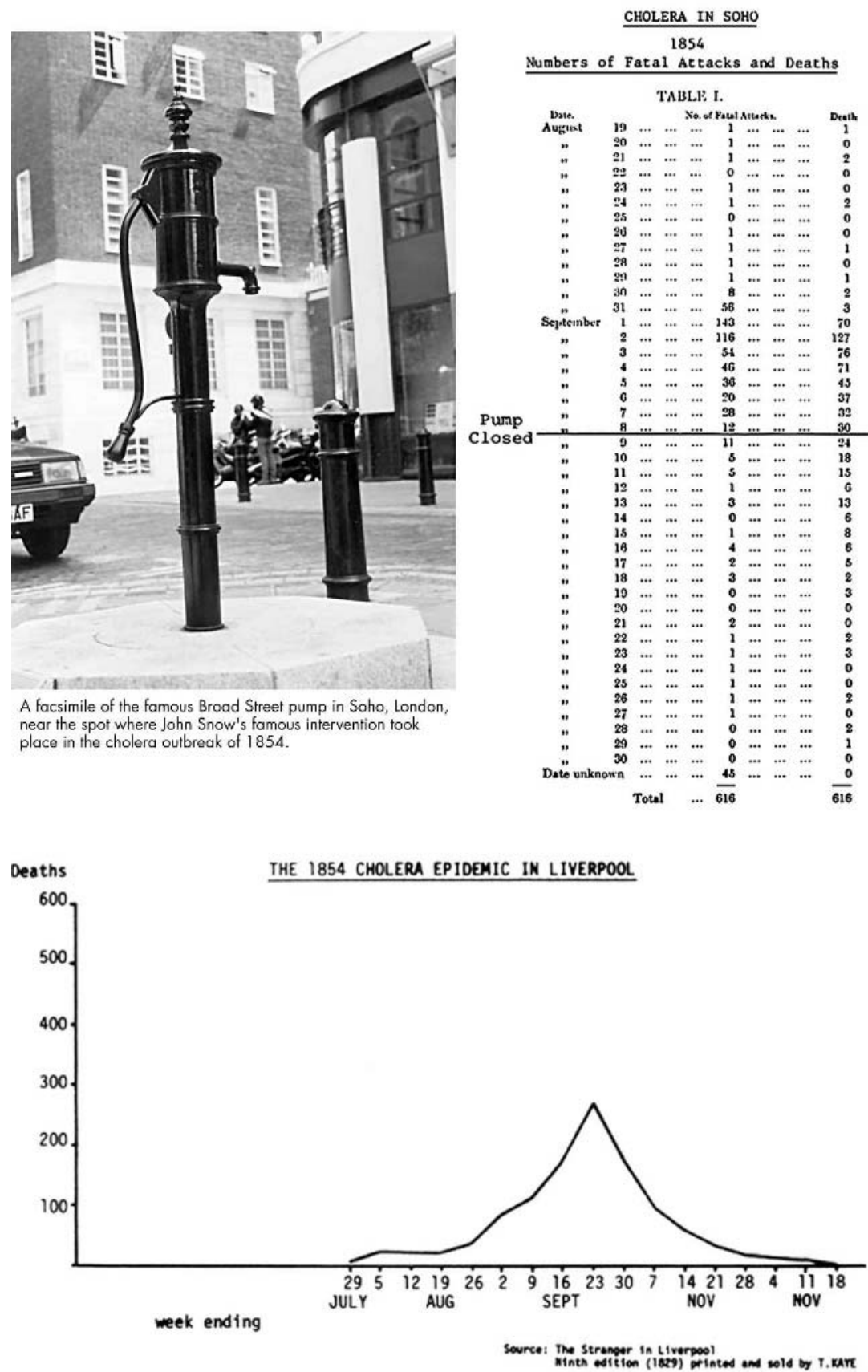